CZASOPISMO INŻYNIERII LACDOWEJ, ŚRODOWISKA I ARCHITEKTURY JOURNAL OF CIVIL ENGINEERING, ENVIRONMENT AND ARCHITECTURE

JCEEA, t. XXXII, z. 62 (3/I/15), lipiec-wrzesień 2015, s. 7-17

Włodzimierz BANACH ${ }^{1}$

Robert SZCZEPANEK ${ }^{2}$

\title{
ZMIANY PARAMETRU CN METODY SCS W DORZECZU GÓRNEJ WISEY, NA PODSTAWIE DANYCH RASTROWYCH CORINE LAND COVER Z LAT 1990-2012
}

\begin{abstract}
Zmienność retencji zlewni ma istotne znaczenie w kształtowaniu się odpływu. Najczęściej stosowaną metodą obliczania wysokości opadu efektywnego, który wywołuje odpływ, jest metoda SCS. Założeniem tej metody jest uzależnienie wysokości opadu efektywnego od rodzaju pokrycia terenu, gleb oraz stanu uwilgotnienia gleby. Wymienione czynniki łączy bezwymiarowy parametr $\mathrm{CN}$ (Curve Number). Proces pozyskiwania danych do metody SCS z map topograficznych jest długotrwały. Wymaga on digitalizacji poszczególnych warstw tematycznych, których aktualizacja dokonywana jest co kilkanaście lat. Alternatywnym źródłem pozyskania danych o zagospodarowaniu terenu sa bazy pokrycia terenu CORINE Land Cover (CLC) opracowane w ramach Europejskiej Agencji Środowiska (EEA) w latach 1990-2012 dla obszaru państw członkowskich Unii Europejskiej. Mapy te dostępne są w formie rastrowej i wektorowej. Mapy gleb dla obszaru państw Unii Europejskiej są udostępniane w ramach projektu European Soil Portal. Wykorzystując te nowoczesne źródła danych rastrowych przeprowadzono analizę zmian wartości parametru CN metody SCS w dorzeczu górnej Wisły na przestrzeni lat 1990 - 2012. W ramach prac zaproponowano schemat reklasyfikacji kategorii danych źródłowych (gleb oraz pokrycia terenu) na kategorie wykorzystywane w metodzie SCS. Efektem prac są rastrowe mapy przestrzennego rozkładu wartości parametru CN w dorzeczu górnej Wisły dla lat 1990, 2000, 2006 oraz 2012. Na zaprezentowanych mapach zidentyfikowano zarówno obszary, na których znaczącej zmianie uległy wartości parametru CN na skutek klęsk żywiołowych, jak i te związane $\mathrm{z}$ urbanizacją oraz rozwojem infrastruktury drogowej w ostatnich latach.
\end{abstract}

Słowa kluczowe: retencja zlewni, opad efektywny, mapa pokrycia terenu, Eurosoils, mapa gleb

\footnotetext{
${ }^{1}$ Autor do korespondencji/corresponding author: Włodzimierz Banach, Państwowa Wyższa Szkoła Wschodnioeuropejska w Przemyślu, ul. Żołnierzy 1 Armii Wojska Polskiego 1E, 37-700 Przemyśl, tel. 1673552 54, wbanach@pwsw.pl

2 Robert Szczepanek, Politechnika Krakowska, ul. Warszawska 24, 30-155 Kraków, tel. 12374 20 80, robert.szczepanek@iigw.pk.edu.pl
} 


\section{Wstęp}

Zagadnienia związane $\mathrm{z}$ modelowaniem hydrologicznym dotyczą w pierwszym rzędzie transformacji opadu efektywnego w odpływ powierzchniowy. Większość zlewni w Polsce ma charakter zlewni niekontrolowanych, z tego powodu do obliczania opadu efektywnego najczęściej stosowana jest amerykańska metoda Soil Conservation Service (SCS) [2]. Metoda ta oparta jest na znajomości rodzaju pokrycia terenu oraz rodzaju gleb występujących w obszarze zlewni. Dotychczas dane tego typu były najczęściej pozyskiwane poprzez digitalizację map topograficznych, jednak taka metoda przygotowania danych wejściowych jest bardzo pracochłonna i podatna na błędy. Należy także pamiętać o tym, że mapy topograficzne nie są aktualizowane zbyt często a ich nowe wersje pociągają za sobą konieczność ponownej digitalizacji.

Wyjściem z tej sytuacji może być wykorzystanie tematycznych map pokrycia terenu opracowanych w ramach Europejskiej Agencji Środowiska (EEA - European Enviroment Agency) dla wszystkich państw członkowskich Unii Europejskiej. Programem monitorującym zmiany zagospodarowania terenu jest CORINE Land Cover (CLC) [http://www.eea.europa.eu/]. Mapy glebowe $\mathrm{w}$ postaci warstw rastrowych dostępne są w ramach innego europejskiego projektu - Eurosoils [http://eusoils.jrc.ec.europa.eu/].

Wykorzystując dane pochodzące $\mathrm{z}$ podanych powyżej źródeł można znacznie przyspieszyć określenie wartości parametru CN metody SCS oraz wielkości opadu efektywnego. Brak jest jednak jasnych wytycznych odnośnie konwersji kategorii pokrycia terenu oraz gleb pochodzących z opisanych projektów europejskich do metody amerykańskiej SCS. Na podstawie dostępnych map rastrowych zagospodarowania terenu $\mathrm{z}$ lat 1990-2012, pochodzących z projektu CLC oraz map kategorii gleb z projektu Eurosoils dokonano analizy zmian wartości parametru CN metody SCS na obszarze wybranych zlewni dorzecza górnej Wisły.

\section{Metoda SCS}

Metoda SCS została opracowana przez Służbę Ochrony Gleb (Soil Conservation Service) w 1954 roku w USA. Jest najpowszechniejszą metodą określenia opadu efektywnego w zlewniach niekontrolowanych [2]. Metoda ta uzależnia opad efektywny od takich czynników jak: rodzaj pokrycia terenu, rodzaj gleb oraz stan uwilgotnienia gleby przed wystąpieniem opadu [2,3]. Gleby zostały podzielone na podstawie wartości współczynnika filtracji na cztery grupy przepuszczalności: A, B, C, D [6, 7]. Zdolność retencyjna zlewni określana jest poprzez bezwymiarowy parametr $\mathrm{CN}$ (Curve Number), wyznaczany na podstawie stabelaryzowanego pokrycia terenu oraz grup przepuszczalności gleb $[2,5]$. Parametr CN przyjmuje wartości w zakresie od 0 dla obszarów całkowicie przepuszczalnych, do wartości 100 dla obszarów całkowicie nieprzepuszczal- 
nych. Te skrajne wartości parametru $\mathrm{CN}$ w praktyce jednak nie występują. W zależności od stanu uwilgotnienia gleby w zlewni wyróżniono jej trzy stany określane jako AMC (Antecendent Moisture Conditions). Przeciętny stan uwilgotnienia gleby określa stan AMC II. Stan uwilgotnienia gleby jest wyrażany przez sumę opadów w okresie pięciu dni poprzedzających opad wywołujący wezbranie.

\section{Mapa pokrycia terenu}

Program CORINE Land Cover (CLC) (Coordination of Information on the Environment) jest jedną z metod monitoringu zagospodarowania terenu na terenie Unii Europejskiej. Powstałe w wyniku jego prac w latach 1990 - 2012 bazy pokrycia terenu zostały zrealizowane w większości krajów członkowskich Unii Europejskiej. Koordynacją oraz aktualizacja danych zajmuje się Agencja Ochrony Środowiska (EEA). Głównym źródłem pozyskiwania informacji o pokryciu terenu są zdjęcia z satelity Landsat (skaner ETM), francuskiego satelity Spot oraz indyjskiego satelity IRS. Satelita Landsat wykonuje zdjęcia $\mathrm{z}$ rozdzielczością terenową $30 \mathrm{~m}$, Spot $\mathrm{z}$ rozdzielczością terenową $20 \mathrm{~m}$, a IRS z rozdzielczością terenową $23,5 \mathrm{~m}$. Do zadań programu CLC należy m.in. zbieranie informacji na temat stanu środowiska naturalnego, koordynacja gromadzenia danych, udostępnianie informacji o środowisku oraz zapewnienie spójności informacji. Mapy, które są udostępniane w ramach programu CLC wykonane są zarówno w wersji wektorowej jak i rastrowej. Rastrowe mapy posiadają rozdzielczość przestrzenną $100 \mathrm{~m}$.

Do tej pory zostały zrealizowane cztery projekty CORINE Land Cover. Celem pierwszego projektu (CLC1990) było stworzenie bazy pokrycia terenu w roku 1990. Wyniki uzyskane z następnych programów: CLC2000, CLC 2006 i CLC2012 stanowiły aktualizację bazy pokrycia terenu jak również pozwoliły na utworzenie bazy prezentującej zmiany, jakie zaszły w pokryciu terenu od 1990 roku.

W programie CLC wyróżniono klasy pokrycia terenu na trzech poziomach. „Pierwszy poziom obejmuje pięć głównych typów pokrycia globu ziemskiego: tereny antropogeniczne, obszary rolnicze, tereny leśne i pótpustynne, mokradta oraz wody. Na drugim poziomie zostato wyróznionych 15 form pokrycia terenu, które można przedstawić na mapach w skalach od 1:500000 do 1:1000000. Wreszcie na poziomie trzecim wyróżniono 44 klasy." [10].

Mapy CLC nie są dostępne dla fragmentu zlewni Sanu znajdującej się na terenie Ukrainy. Wszelkie analizy wykonano jedynie dla części zlewni w granicach Polski i nie należy ich traktować jako miarodajne dla zlewni Sanu z hydrologicznego punktu widzenia. Dla roku 2012 dane CLC dostępne były jedynie w postaci usługi przeglądania WMS, jednak przekształcono je do postaci warstw rastrowych o rozdzielczości przestrzennej $100 \mathrm{~m}$. 


\section{Mapa gleb}

Źródłem danych glebowych są mapy opracowane przez Institute for Environment and Sustainability w ramach projektu Eurosoils [4]. Spośród dostępnych w ramach projektu produktów wybrano mapę rastrową FAO85LV1 o rozdzielczości przestrzennej $1000 \mathrm{~m}$. Na mapie tej wyróżniono 33 rodzaje gleb, lecz nie wszystkie z nich występują na obszarze Polski.

Aby możliwe było połączenie danych zawartych na mapach glebowych $\mathrm{z}$ danymi o pokryciu terenu, dokonano resamplingu map glebowych dopasowując ich rozdzielczość do rozdzielczości map pokrycia terenu. Utworzone rastrowe gleb miały rozdzielczość przestrzenną $100 \mathrm{~m}$ i były wpasowane w warstwy rastrowe pokrycia terenu.

\section{Obliczenie wartości parametru $\mathrm{CN}$ w wybranych zlewniach dorzecza górnej Wisły}

Badanie zmian wartości parametru CN w latach 1990-2012 przeprowadzono w dziewięciu zlewniach dorzecza górnej Wisły - Przemszy, Soły, Skawy, Raby, Dunajca, Wisłoka, Wisłoki, Sanu i Nidy.

Pierwszym krokiem była reklasyfikacja (przekodowanie) gleb pozyskanych z projektu Eurosoils do kategorii gleb wykorzystywanych w metodzie SCS (tab. 1). Do wstępnego przygotowania warstw rastrowych, ich reklasyfikacji oraz przetwarzania wykorzystano program QGIS 2.8 [8, 9], dostępne w nim narzędzie Kalkulator rastra oraz moduły programu GRASS.

Tabela 1. Schemat reklasyfikacji gleb FAO85LV1 do gleb w modelu SCS

Table 1. Reclassification scheme of FAO85LV1 soils to SCS model soils

\begin{tabular}{|c|c|c|}
\hline Kod gleb FAO85LV1 & Klasa gleb w metodzie SCS & Kod gleb w metodzie SCS \\
\hline $1,15,27$ & A & 1 \\
\hline $4,11,19,26$ & B & 2 \\
\hline $2,13,14,17$ & C & 3 \\
\hline $8,10,12,25$ & D & 4 \\
\hline
\end{tabular}

Do wyznaczenia wartości parametru $\mathrm{CN}$ w obliczeniach przyjęto przeciętny stopień uwilgotnienia w zlewni odpowiadający poziomowi AMC-II. Z uwagi na brak informacji dotyczących sposobu upraw ziemi oraz warunków hydrologicznych dokonano uśrednienia wartości parametru $\mathrm{CN}$ dla poszczególnych rodzajów pokrycia powierzchni (tab. 2). 
Tabela 2. Schemat reklasyfikacji pokrycia CORINE Land Cover na klasy pokrycia metody SCS; proponowane kody klas SCS; wartości CN w oparciu o podział Ignara opracowano na podstawie [5]

Table 2. Reclassification scheme of CORINE Land Cover to SCS cover classes; proposed codes for SCS classes; CN values after Ignar on the basis of [5]

\begin{tabular}{|c|c|c|c|c|c|c|}
\hline \multirow{2}{*}{ Kod CLC } & \multirow{2}{*}{$\begin{array}{l}\text { Kod dla } \\
\text { klas SCS }\end{array}$} & \multirow{2}{*}{ Rodzaj pokrycia powierzchni } & \multicolumn{4}{|c|}{ Klasa gleb } \\
\hline & & & $\mathbf{A}$ & B & $\mathbf{C}$ & D \\
\hline $7,8,9,27,29,33$ & 1 & Ugór & 77 & 86 & 91 & 94 \\
\hline 20 & 2 & Rośliny okopowe & 67 & 76 & 83 & 86 \\
\hline $12,15,21$ & 3 & Rośliny zbożowe & 62 & 73 & 81 & 85 \\
\hline 16 & 4 & Rośliny motylkowe & 60 & 72 & 81 & 84 \\
\hline $26,35,36$ & 5 & Pastwiska & 52 & 70 & 79 & 84 \\
\hline 14,18 & 6 & Łąki & 30 & 58 & 71 & 78 \\
\hline $23,24,25$ & 7 & Las & 35 & 60 & 73 & 80 \\
\hline 10 & 8 & Zabudowa wiejska & 59 & 74 & 82 & 86 \\
\hline 31 & 9 & Drogi wiejskie gruntowe & 72 & 82 & 87 & 89 \\
\hline 40,41 & 10 & Drogi wiejskie z twardą nawierzchnią & 74 & 84 & 90 & 92 \\
\hline $11,30,32$ & 11 & $\begin{array}{l}\text { Otwarte przestrzenie (parki, cmenta- } \\
\text { rze,...) }\end{array}$ & 44 & 65 & 77 & 82 \\
\hline 3 & 12 & Tereny handlowe i przemysłowe & 89 & 92 & 94 & 95 \\
\hline 1 & 13 & Okręgi przemysłowe & 81 & 88 & 91 & 93 \\
\hline 2 & 14 & Tereny zamieszkałe & 60 & 74 & 83 & 87 \\
\hline $4,5,6$ & 15 & Ulice i drogi miejskie & 87 & 92 & 94 & 95 \\
\hline
\end{tabular}

Po opracowaniu map bazowych gleb oraz pokrycia terenu dla czterech analizowanych lat, wykorzystując wartości $\mathrm{CN}$ opisane w tabeli 2 dokonano przypisania odpowiedniej wartości CN dla poszczególnych kombinacji gleb i pokryć terenu. Uzyskano w ten sposób warstwy rastrowe z wartościami CN dla każdego roku. Następnie obliczono różnicę pomiędzy kolejnymi okresami, czyli stworzono trzy warstwy odpowiednie dla zmian w latach 1990-2000, 20002006 oraz 2006-2012.

Przy pomocy narzędzia Statystyki strefowe programu QGIS obliczono statystyki związane $\mathrm{z}$ wybranymi zlewniami obrazujące zmiany parametru $\mathrm{CN}$ w poszczególnych okresach. Do celów wizualizacji zmian CN dokonano reklasyfikacji map wynikowych w taki sposób, że wyznaczono obszary dla których bezwymiarowy parametr $\mathrm{CN}$ zwiększył się lub zmniejszył o więcej niż 5 jednostek (rys.1-3). Pozwoliło to na stworzenie dwóch map zmian (wzrost/spadek CN) dla każdego roku.

Mapy wynikowe w postaci warstw rastrowych o rozdzielczości przestrzennej $100 \mathrm{~m}$ dla całego dorzecza górnej Wisły, zostały udostępnione publicznie pod adresem http://openhydrology.org/hydrological_data. 


\section{Analiza wyników}

W wyniku analiz uzyskano cztery warstwy rastrowe, po jednej dla każdego analizowanego roku (1990, 2000, 2006, 2012), obrazujące przestrzenną zmienność parametru CN metody SCS w dorzeczu górnej Wisły (tab. 3).

Tabela 3. Zmiany średniej wartości parametru CN [-] w latach 1990-2012 dla wybranych zlewni dorzecza górnej Wisły; wyróżniono największe wzrosty i spadki wartości CN

Table 3. Changes of average CN [-] in years 1990-2012 for selected catchments in upper Vistula basin; highest and lowest $\mathrm{CN}$ values changes are highlighted

\begin{tabular}{|l|c|c|c|}
\hline Zlewnia & $\begin{array}{c}\text { lata } \\
\mathbf{1 9 9 0 - 2 0 0 0}\end{array}$ & $\begin{array}{c}\text { lata } \\
\mathbf{2 0 0 0 - 2 0 0 6}\end{array}$ & $\begin{array}{c}\text { lata } \\
\mathbf{2 0 0 6 - 2 0 1 2}\end{array}$ \\
\hline Dunajec & 0,16 & 0,10 & 0,23 \\
\hline Nida & 0,05 & $-0,16$ & $-0,07$ \\
\hline Przemsza & 0,20 & $-0,62$ & $-1,23$ \\
\hline Raba & 0,01 & $-0,17$ & $-0,17$ \\
\hline San & $-0,05$ & $-0,07$ & 0,01 \\
\hline Skawa & 0,00 & $-0,05$ & $-0,65$ \\
\hline Soła & 0,18 & $-0,33$ & 0,30 \\
\hline Wisłok & 0,00 & $-0,31$ & $-0,31$ \\
\hline Wisłoka & 0,00 & $-0,21$ & $-0,34$ \\
\hline
\end{tabular}

Zwracają uwagę duże zmiany wartości parametru $\mathrm{CN}$ w zlewniach, które charakteryzują się największą zmiennością przepływów w analizowanym rejonie i powodują corocznie znaczne straty powodziowe - Dunajec i Soła.

Na szczególną uwagę zasługą trzy przypadki znacznych zmian wartości parametru CN, które zostały zaprezentowane na rysunkach 1, 2 i 3. Związane są one zarówno z działalnością sił natury, przemianami antropogenicznymi jak i błędami ludzkimi.

Efekt działania sił natury można zaobserwować w zlewni Dunajca, a dokładniej w zlewni jego dopływu - Popradu (rys. 1). W listopadzie 2004 roku wskutek przemieszczania się układu niżowego przez Karpaty wystąpił silny wiatr (jego prędkość wynosiła do ok. $230 \mathrm{~km} / \mathrm{h}$ ). Huragan dotknął najbardziej obszaru położonego na południowych stokach Tatr Wysokich powodując ogromne spustoszenia w drzewostanie [1]. Pokotem legły lasy od Podbańskiej u zachodnich podnóży Krywania do Tatrzańskiej Kotliny na wschodnim skraju Tatr Bielskich. Obszar wiatrołomów rozciągał się na północ od granicy Tatranského Národného Parku i obejmował powierzchnię ok. 14000 ha. 
Zniszczeniu uległy głównie monokultury świerkowe. Leżące w pasie huraganu miejscowości turystyczno-wypoczynkowe także uległy sile wiatru zniszczonych zostało wiele obiektów sanatoryjnych, hotelowych oraz willowych.

Kataklizm ten spowodował zmiany we współczynniku CN nieporównywalne ze zmianami antropogenicznymi zaobserwowanymi w okresie 1990-2012 w dorzeczu górnej Wisły.

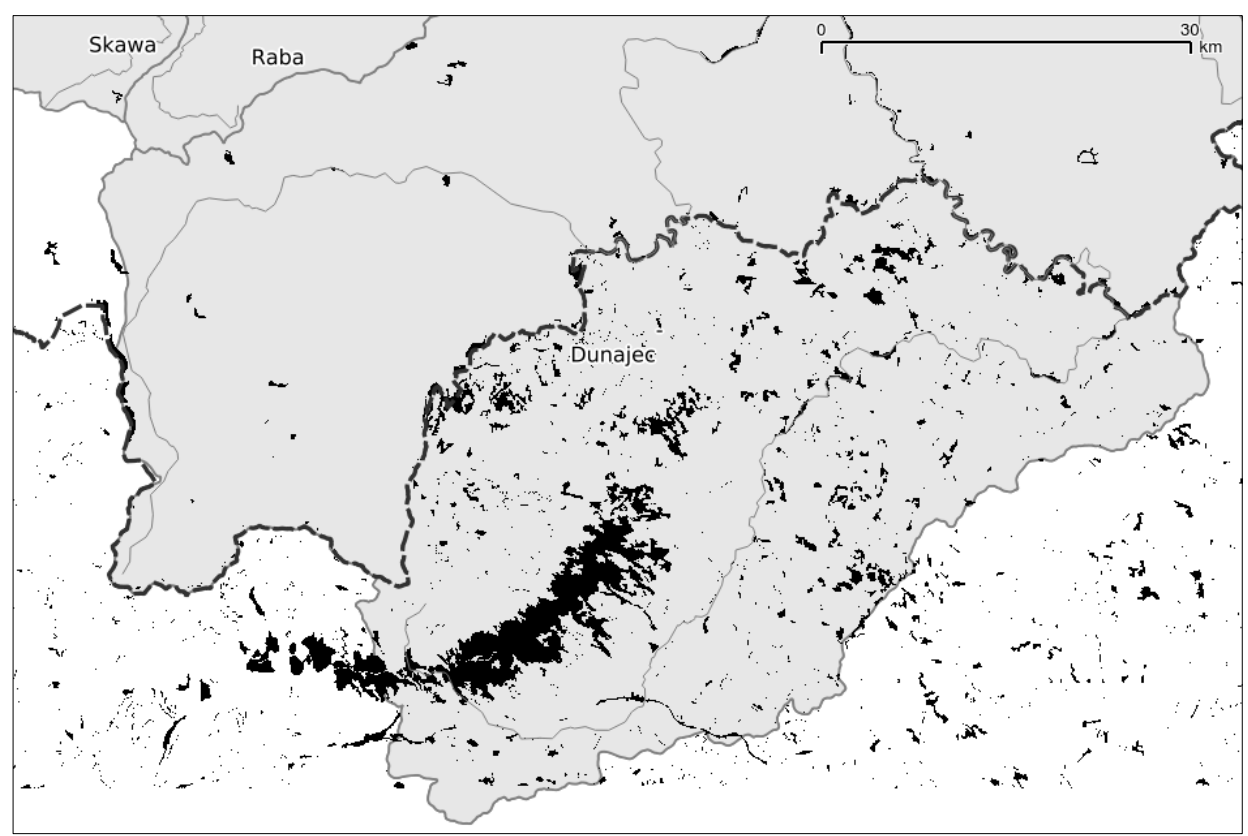

Rys. 1. Obszary, na których parametr CN zwiększył się co najmniej o 5 w latach 2000-2006; fragment zlewni Dunajca na granicy Polsko-Słowackiej; obszar zniszczeń lasów po huraganie z 2004 roku na południowych zboczach Tatr

Fig. 1. Areas where CN parameter increased by 5 or more in years 2000-2006; part of Dunajec watershed on Polish-Slovak border; area after hurricane in year 2004 on southern slopes of Tatra mountains 
Działalność antropogeniczna jest także dostrzegalna na mapach zmian wartości parametru $\mathrm{CN}$. W latach obejmujących szybką rozbudowę infrastruktury w Polsce związaną z funduszami europejskimi, łatwo można zaobserwować liniowe struktury będące elementami sieci drogowej.

Na rysunku 2 można odnaleźć nowo wybudowany fragment autostrady A-4 w okolicach Tarnowa, która ma przebieg z zachodu na wschód. Jest to jedynie przykład, ponieważ takich obiektów można dla tego okresu zaobserwować znacznie więcej.

Drugą kategorią obszarów z dobrze widocznymi zmianami są obrzeża miast i miejscowości, które podlegały w tym okresie procesowi urbanizacji. Takich przykładów postępującej urbanizacji można znaleźć na wynikowych mapach bardzo wiele, nie tylko na prezentowanych zlewniach Dunajca i Wisłoki.

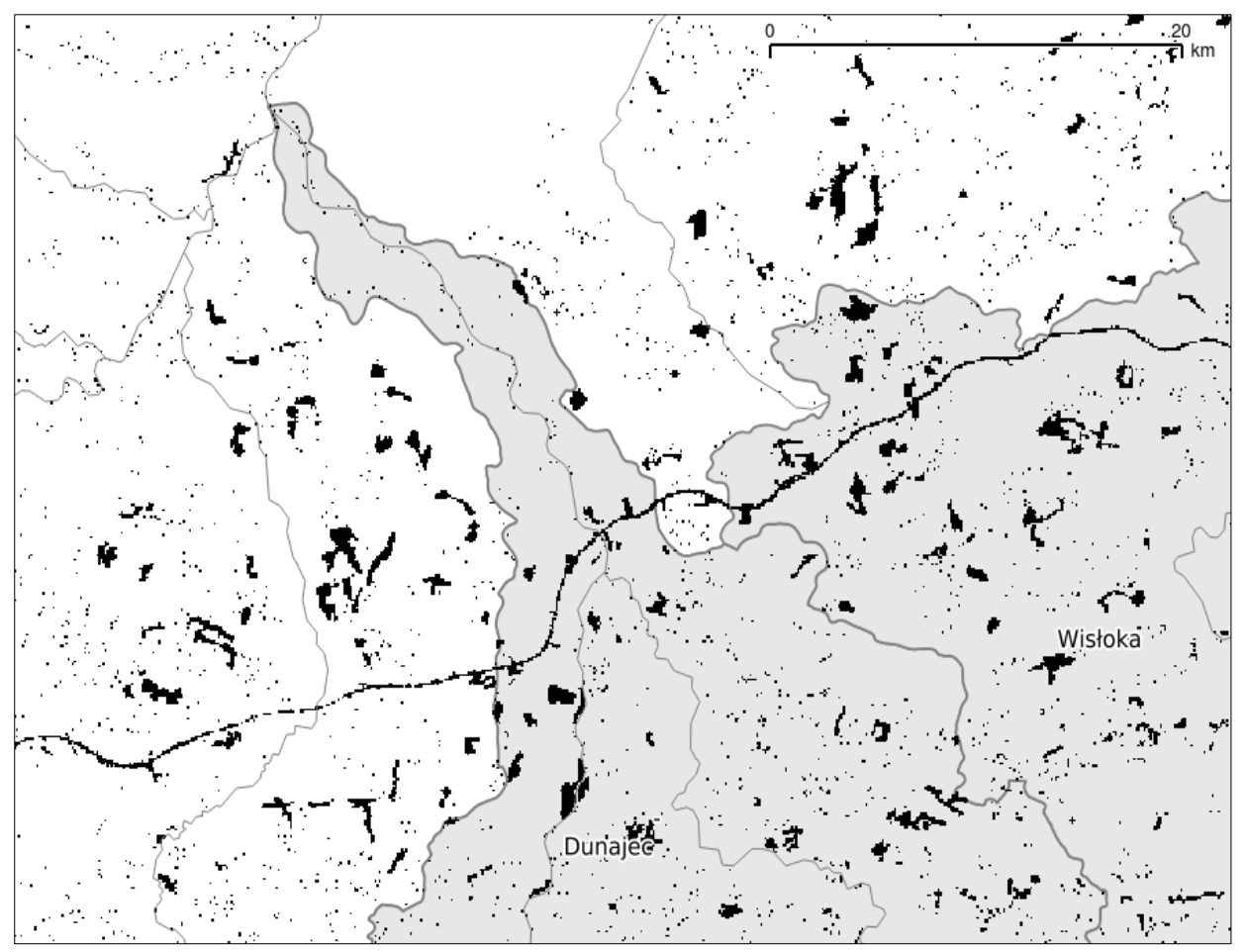

Rys. 2. Obszary, na których parametr CN zwiększył się co najmniej o 5 w latach 2006-2012; widoczny fragment nowej autostrady A-4 w okolicach Tarnowa - ujście Dunajca do Wisły

Fig. 2. Areas where CN parameter increased by 5 or more in years 2006-2012; visible part of new A-4 highway in Tarnów area - Dunajec outlet to Vistula river 
W zlewni rzeki Przemszy w latach 2006-2012 zaobserwowano znaczące zmniejszenie wartości parametru CN (rys. 3, tab. 3). Obszary, które podlegały zmianom to w znakomitej większości miejsca, gdzie w roku 2006 na mapach CLC występowała kategoria 12 (2.1.1 Grunty orne poza zasięgiem urzadzeń nawadniających), zaś w roku 2012 pojawiła się w tym miejscu kategoria 14 (2.1.3 Ryżowiska). Powód tych zmian wynika z błędnego zakodowania tej kategorii na serwerze WMS, z którego pobierana była warstwa dla roku 2012. Kategoria 12 CLC powinna być kodowana jako RGB o składowych 255-255-168, zaś została zakodowana tak jak kategoria 14 o składowych RGB 230-230-000.

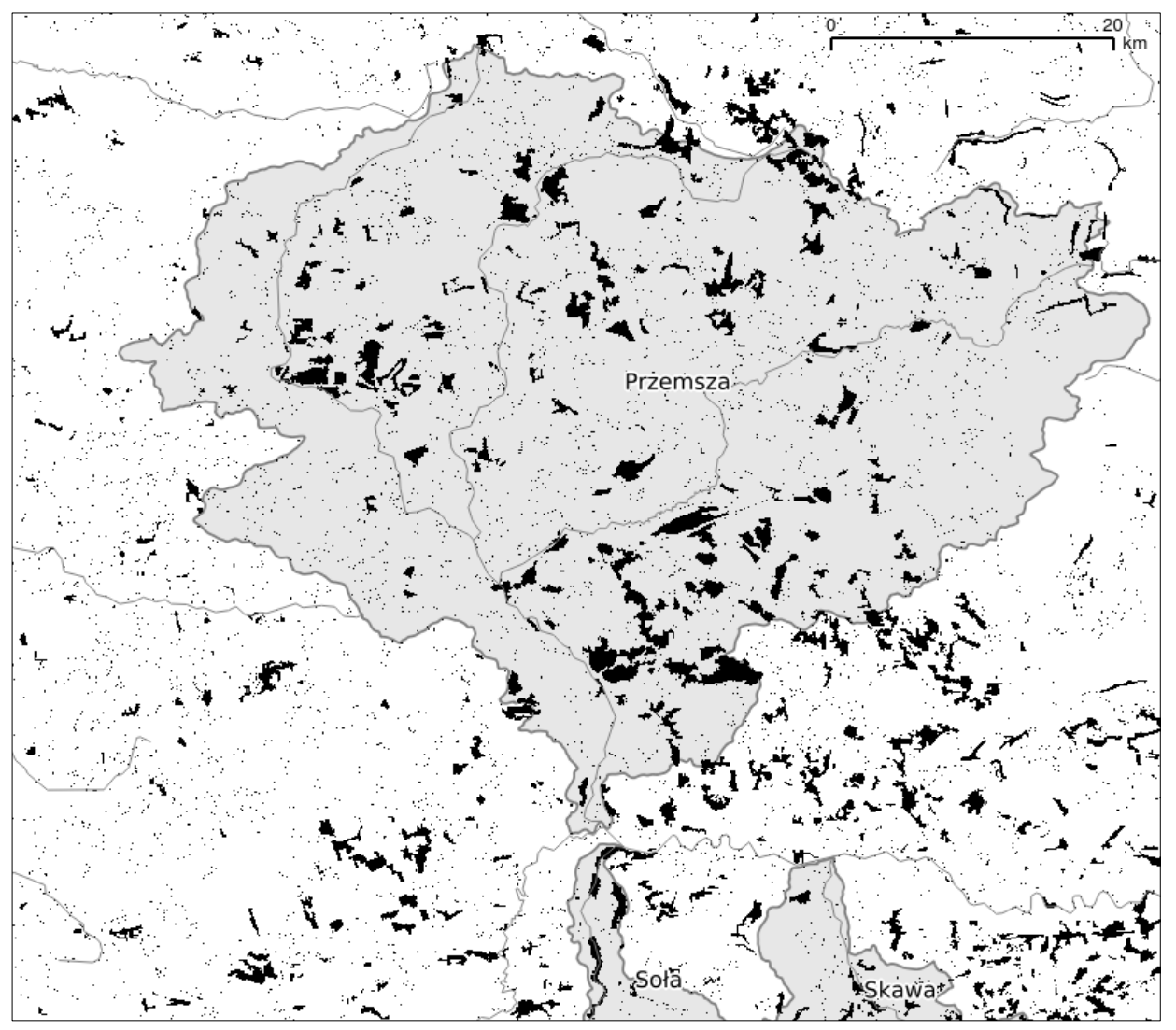

Rys. 3. Obszary w zlewni Przemszy, na których parametr $\mathrm{CN}$ zmniejszył się co najmniej o 5 w latach 2006-2012

Fig. 3. Areas in Przemsza watershed, where CN parameter decreased by 5 or more in years 2006-2012 


\section{Wnioski}

W latach 1990-2000 nie zaobserwowano większych zmian wartości parametru CN w dorzeczu górnej Wisły.

W latach 2000-2006 największe zmiany wartości parametru CN wystąpiły na terenie zlewni rzeki Soły oraz Wisłoka. Są to wartości, które świadczą o zwiększeniu retencyjności zlewni. W mniejszej skali dotyczy to pozostałych zlewni, oprócz Dunajca, gdzie retencyjność nieznacznie się obniżyła.

W latach 2006-2012 wyraźnie zauważalne są zmiany parametru $\mathrm{CN}$ zarówno zwiększające jak i zmniejszające retencyjność poszczególnych zlewni cząstkowych.

Najbardziej niekorzystne zmiany parametru $\mathrm{CN}$ w analizowanym okresie (1990-2012) zaobserwowano w zlewni Dunajca, co w dłuższej perspektywie może skutkować bardziej gwałtownymi powodziami. Najbardziej widoczna zmiana związana była z klęską żywiołową - huraganem w południowej części zlewni Dunajca.

Spośród oddziaływań antropogenicznych zwraca uwagę postępująca w latach 2006-2012 urbanizacja oraz rozwój sieci komunikacyjnych. Mają one niekorzystny wpływ na kształtowanie się odpływu powierzchniowego poprzez zmniejszanie retencyjności obszaru zlewni.

Jedną z największych zalet wykorzystania do analiz środowiskowych danych z projektu CORINE Land Cover jest $\mathrm{z}$ całą pewnością ich jednorodność dla całego obszaru Unii Europejskiej oraz cykliczna aktualizacja. Wydaje się, że w przyszłości stanowić one będą warstwy referencyjne ułatwiając przenoszenie modeli hydrologicznych do dowolnej zlewni na obszarze UE.

Praca została wykonana w ramach projektu Ś-1/230/2015/DS, Zadanie 4. Ocena zmienności przeptywu rzek i potoków zlewni Raby - etap 3.

\section{Literatura}

[1] Balon J., Maciejowski W.: Wpływ huraganowego wiatru z dnia 19 listopada 2004 na krajobraz południowego skłonu Tatr, Problemy Ekologii Krajobrazu 17.17, 2014.

[2] Banasik K.: Model sedymentogramu wezbrania opadowego w małej zlewni rolniczej, Wydawnictwo SGGW, Warszawa 1994.

[3] Banasik K., Ignar J.: Wyznaczanie hydrogramów wezbrań opadowych z małych nieobserwowanych zlewni rolniczych, Wydawnictwo SGGW, Warszawa 1994.

[4] Eurosoils [http://eusoils.jrc.ec.europa.eu/], [dostęp: 05.05.2015 r.].

[5] Ignar S.: Metoda SCS i jej zastosowanie do wyznaczania opadu efektywnego, Przegląd Geofizyczny, XXXIII, z. 4., 1988.

[6] Kolerski T.: Praktyczne aspekty gospodarki wodnej w projektowaniu zbiorników retencyjnych, Wydawnictwo Politechniki Gdańskiej, Gdańsk 2014.

[7] Pociask - Karteczka J.: Zlewnia. Właściwości i procesy, Wydanie drugie, zmienione, Wydawnictwo UJ, Kraków 2006. 
[8] QGIS Development Team, 2015. QGIS Geographic Information System. Open Source Geospatial Foundation Project. (http://qgis.osgeo.org) [dostęp: 05.05.2015 r.].

[9] Szczepanek R.: Quantum GIS - wolny i otwarty system informacji geograficznej, Czasopismo Techniczne z.4-Ś/2012, Wydawnictwo Politechniki Krakowskiej, s.171-182, Kraków 2012.

[10] http://www.clc.gios.gov.pl/index.php [dostęp: 05.05.2015 r.].

\title{
CHANGES OF CN PARAMETER FOR SCS METHOD IN UPPER VISTUAL BASIN, BASED ON RASTER CORINE LAND COVER DATA FROM YEARS 1990-2012
}

\begin{abstract}
S u m m a r y
Changes of watershed retention are important in runoff formation process. One of the most popular method of excess rainfall calculation, which forms runoff, is SCS method. As the assumption of this method, excess rainfall depends on land cover, soil type and antecedent soil moisture. Presented factors are coupled by non-dimensional parameter CN (Curve Number). Data preparation for SCS method from topographic maps is time consuming. It requires digitalization of several thematic layers, which are updated every few years. An alternative source of land cover data are CORINE Land Cover project databases (CLC) developed within European Environment Agency (EEA) in years 1990-2012 for European Union countries. These maps are available in raster and vector format. Soil maps for EU countries are published within European Soil Portal. Using those modern data sources, analysis of changes in CN parameter values of SCS method was performed for upper Vistula basin for years 1990-2012. Scheme of source data (land cover and soil) reclassification to SCS categories was proposed. The result of presented work are raster maps of spatial distribution of CN parameter in upper Vistula basin for years 1990, 2000, 2006 and 2012. On presented maps, areas with substantial changes of $\mathrm{CN}$ value as result of natural disaster and those related to urbanization and road development in recent years were identified.
\end{abstract}

Keywords: watershed retention, excess rainfall, land cover map, Eurosoils, soil map

Przestano do redakcji:30.05.2015

Przyjęto do druku:1.12.2015

DOI: $10.7862 / \mathrm{rb} .2015 .91$ 